\title{
Effect of Diatomite Weight Fraction on Morphology, Thermal and Physical Properties of Diatomite Filled High Density Polyethylene Composites
}

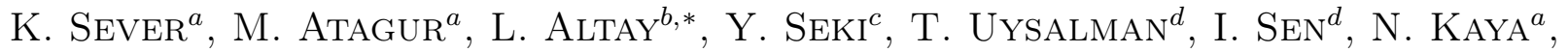 \\ A. GUVEN ${ }^{e}$ AND M. SARIKANAT ${ }^{b}$ \\ ${ }^{a}$ Izmir Katip Celebi University, Faculty of Engineering and Architecture, Cigli, Izmir, Turkey \\ ${ }^{b}$ Ege University, Mechanical Engineering Department, Bornova, Izmir, Turkey \\ ${ }^{c}$ Dokuz Eylul University, Faculty of Science, Buca, Izmir, Turkey \\ ${ }^{d}$ Izmir Egitim Saglik Sanayi Yatirim A.S., Turgutlu, Manisa, Turkey \\ eAnkara Yıldırım Beyazıt University, Mechanical Engineering Department Kecioren, Ankara, Turkey

\begin{abstract}
High density polyethylene (HDPE) has been used extensively in many sectors of the industry. The main reason for the frequent use of HDPE is its low cost, easy processing, and high performance. These sectors include household and garden products, packaging etc. In order to reduce the production cost of plastic products and to improve plastic's moldability and stability, one or more minerals are usually filled into the thermoplastics. The minerals commonly used as fillers in plastic molding compounds include calcium carbonate, talc, silica, wollastonite, clay, mica, glass beads, and alumina trihydrate. In this paper, diatomite (DA) filled HDPE composites were prepared with gelimat mixer and hot press molding technique. Thermal properties of the composites were studied by thermogravimetric analysis and dynamic mechanical analysis. The mechanical properties of the composites were determined by using universal testing machine. Morphology of the composites was investigated by scanning electron microscopy. With the addition of DA into HDPE, significant change in tensile and flexural strengths of HDPE was not observed. The loss and storage moduli increased with increasing weight fraction of DA.
\end{abstract}

DOI: 10.12693/APhysPolA.134.281

PACS/topics: polyethylene composites, diatomite, thermal properties, mechanical properties

\section{Introduction}

HDPE is the one of the most commonly used thermoplastics due to diversified amount of physical properties, including higher hardness, tensile strength, heat soft point, chemical and water resistance, easy processing, and low cost [1]. However, HDPE has some limitations, such as high mould shrinkage and thermal expansion [2]. Therefore, they are mostly filled with mineral fillers which have higher moduli than polymers to improve their strength, modulus, heat stability and low cost as well [3, 4]. Liang et al. (2007) studied the mechanical, thermal, and flow properties of HDPE filled with mica, and the results showed that tensile yield strength and tensile break strength increased with increasing weight fraction of the filler. In the same study, heat durability was improved however the melt volume flow rate of HDPE composite decreased with increasing weight fraction of the mica [5]. Karrad et al. (1998) studied the effect of talc on the properties of HDPE and HDPE/polystyrene blends [6].

DA is widely known as a kind of siliceous mineral which generally exhibits cheaper cost, higher in quantity and good filtering capability [7]. The properties allow DA

*corresponding author; e-mail: lutfiyebulut@gmail.com to be an effectively usable as a filler for $\operatorname{HDPE}[8,9]$. Some of the most common usages of DA have been in coatings, rubber, and plastic manufacturing. DA filled HDPE composites were produced by a single-screw extruder and rheological, mechanical, and morphological properties were investigated by De Sousa [10]. However, it is known that high speed thermokinetic mixer with no external heat source, low operating cost, and less thermal degradation due to short processing times, has attracted attention. More recently, in order to obtain a better dispersion of filler material in the polymer matrix for crucial compounding applications, thermokinetic mixer has started to be utilized [11]. Up to now, DA filled HDPE composites have not been studied with details. Therefore, in this study, DA filled HDPE composites were prepared with a high speed thermokinetic mixer and hot press molding technique. The aim of this study is to investigate the effect of DA weight fraction on morphological, thermal, mechanical, and viscoelastic properties of HDPE.

\section{Materials and methods}

\subsection{Materials and composite preparation}

The matrix material is HDPE (S 0452) supplied by Izmir Egitim Saglik Sanayi Yatirim A.S., Turkey. The density of HDPE is $0.95 \mathrm{~g} / \mathrm{cm}^{3}$. DA with a particle size of $50 \mu \mathrm{m}$ and a density of $3.02 \mathrm{~g} / \mathrm{cm}^{3}$ was used as a 
filler in this study. HDPE based composites with 5, 10, 15, 20 wt\% (HDPE-5DA, HDPE-10DA, HDPE-15DA, and HDPE-20DA) were manufactured by using a high speed thermokinetic mixer (Gülnar Makina, Turkey). DA-HDPE mixtures were processed about $15-20 \mathrm{~s}$ at $2000 \mathrm{rpm}$ in order to obtain composites whose plates were produced by using hydraulic hot and cold press (Gülnar Makina, Turkey).

\subsection{Characterization methods}

TGA was made on TA Instrument Q600 model simultaneous thermal analysis equipment. Measurements were recorded at a heating rate of $10^{\circ} \mathrm{C} / \mathrm{min}$ from room temperature to $600^{\circ} \mathrm{C}$. TA Instrument Q800 dynamic mechanical analyzer was used to determine the viscoelastic behavior of HDPE and its composites. Specimens $(35 \times 10 \times 3 \mathrm{~mm})$ were measured in single cantilever bending mode at a frequency of $1 \mathrm{~Hz}$ in a temperature ramp mode. The samples were heated from 35 to $145^{\circ} \mathrm{C}$ at a heating rate of $3{ }^{\circ} \mathrm{C} / \mathrm{min}$. Tensile testing specimens were tested using a Shimadzu Autograph AG-IS Series universal testing machine at a crosshead speed of $50 \mathrm{~mm} / \mathrm{min}$ according to ASTM standard D638-10. Three-point bending tests were conducted to characterize the flexural properties of the HDPE and its composites by following the ASTM D790 standard. The tests were carried out at a constant crosshead speed of $2 \mathrm{~mm} / \mathrm{min}$. Three tests were performed for each specimen for thermal and mechanical characterization.

\section{Results and discussion}

Thermal degradation behavior of HDPE and its composites were obtained from TGA curves as shown in Fig. 1.

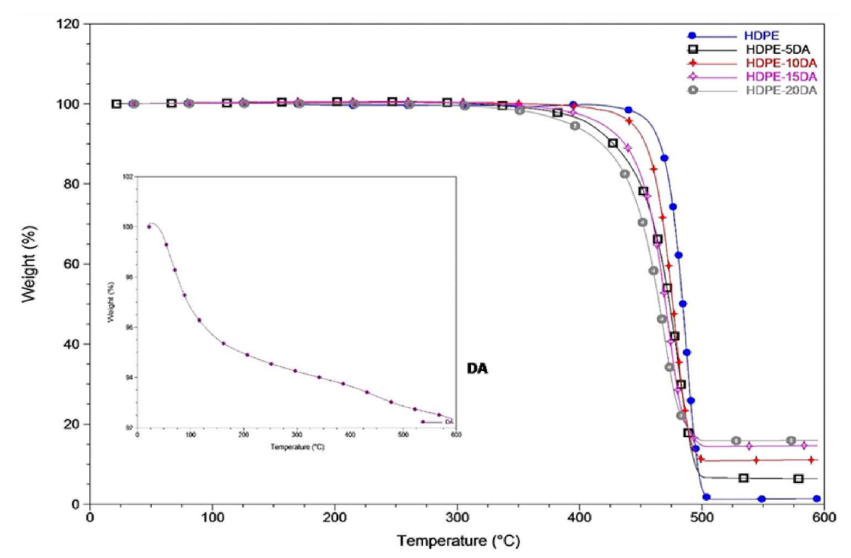

Fig. 1. TGA curves of HDPE and DA filled HDPE composites.

Thermal degradation temperature of HDPE was dramatically decreased by increasing DA content into HDPE matrix. Maximum degradation temperatures for HDPE and its composites were obtained to be 497.0, 493.0,
489.6, 485.5, and $483.0^{\circ} \mathrm{C}$, respectively. According to Fig. 1, DA caused almost $7 \%$ decrease in thermal endurance of the HDPE matrix. Thermal degradation residue of composites was increased by increasing DA content. DA had a high thermal resistivity and a mass loss of about $7.7 \%$ at $600{ }^{\circ} \mathrm{C}$ due to removal of volatile matter of DA.

Figure 2 shows the variation of storage and loss moduli as a function of temperature for HDPE and its composites. From Fig. 2a, a decreasing trend is seen in the storage modulus for HDPE and its composites with increasing temperature. This may be ascribed to that thermal motion of the segments of the side chains of polymer becomes easier because of the rise in thermal energy [12]. Storage modulus values of HDPE-5DA at lower temperatures are lower than those of HDPE, which may be ascribed to pseudo lubricating effect of low content of DA particles. It is probable that DA particles make the slippage of methylene groups of the HDPE chains over each other easy [12]. However, $10 \mathrm{wt} \%$ of DA has not led to lubricating effect. The values of storage modulus of HDPE-10DA, HDPE-15DA, and HDPE-20DA are
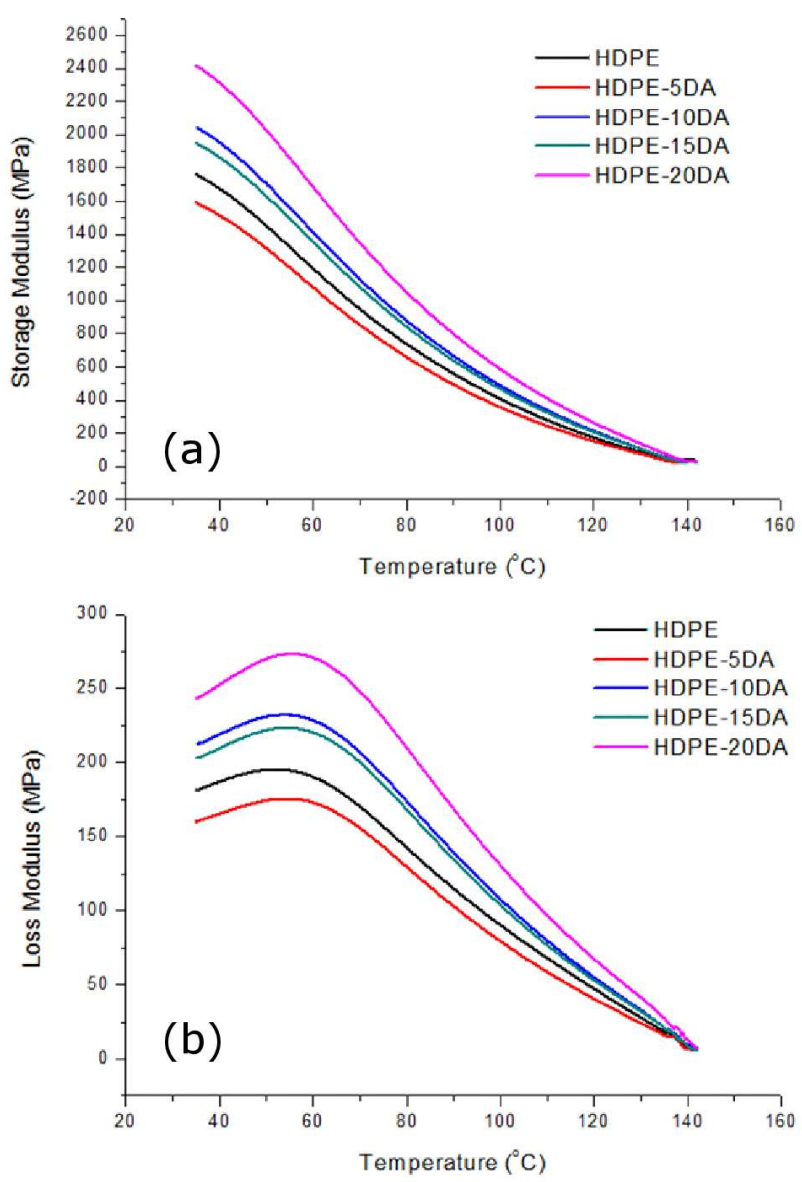

Fig. 2. Plots of (a) storage modulus and (b) loss modulus as a function of temperature for HDPE and its composites. 
larger than those of HDPE because of the mechanical restraints exhibited by DA particles. Maximum dissipation of heat occurs at the peak maxima of 49.7, 53.7, 53.9, 54.3 , and $54.8^{\circ} \mathrm{C}$, for HDPE, HDPE-5DA, HDPE-10DA, HDPE-15DA, and HDPE-20DA, respectively (Fig. 2b). The peak with a maximum temperature of $49.7^{\circ} \mathrm{C}$ for HDPE is due to $\alpha$ transitions.

Figure 3a,b shows tensile and flexural properties of HDPE and its composites, respectively. It is seen that 20 wt\% DA filling into the HDPE matrix did not change the tensile and flexural strength of HDPE considerably the reason of which could be the good dispersion of DA in composites. It was observed that tensile and flexural moduli of HDPE are about 1198 and $1048 \mathrm{MPa}$, respectively and increased with the addition of DA in the studied weight fraction ranges (Fig. 3). Thereby, filling of DA into HDPE limits the mobility and increases the stiffness of HDPE.

SEM micrographs of HDPE-5DA, HDPE-10DA, HDPE-15DA, and HDPE-20DA are given in Fig. 4. In Fig. 4a,b, DA particles, in $\mu \mathrm{m}$ size, were dispersed separately. With the increase in weight fraction of DA, particles were dispersed more closely to each other. Irregular DA particles at different sizes can be clearly seen in Fig. 4c. As shown in Fig. 4d, DA particles were distributed homogeneously within HDPE matrix. The existence of bare particles and holes indicate a poor adhesion between HDPE matrix and DA particles.
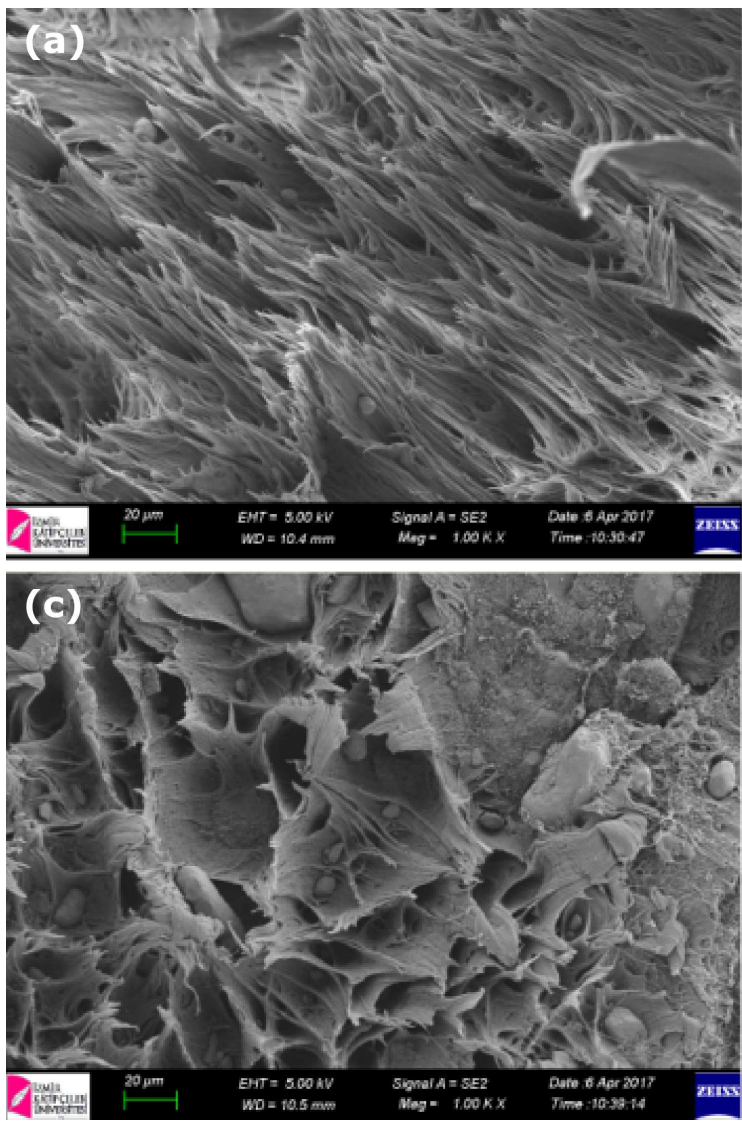
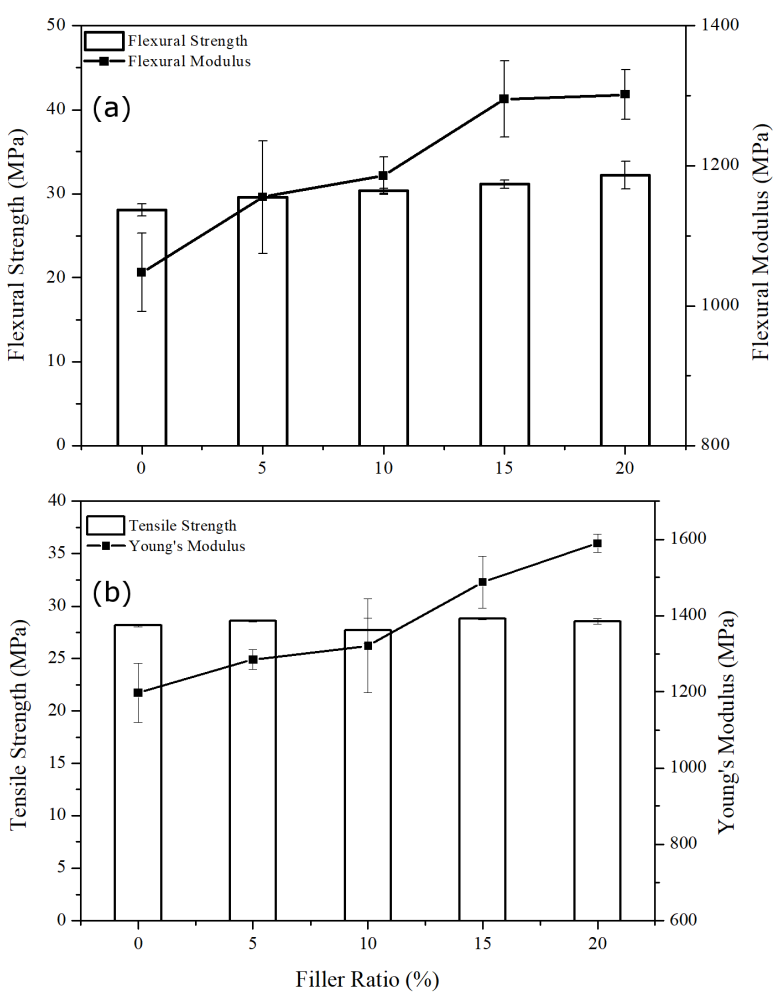

Fig. 3. (a) Tensile and (b) flexural properties for HDPE and its composites.
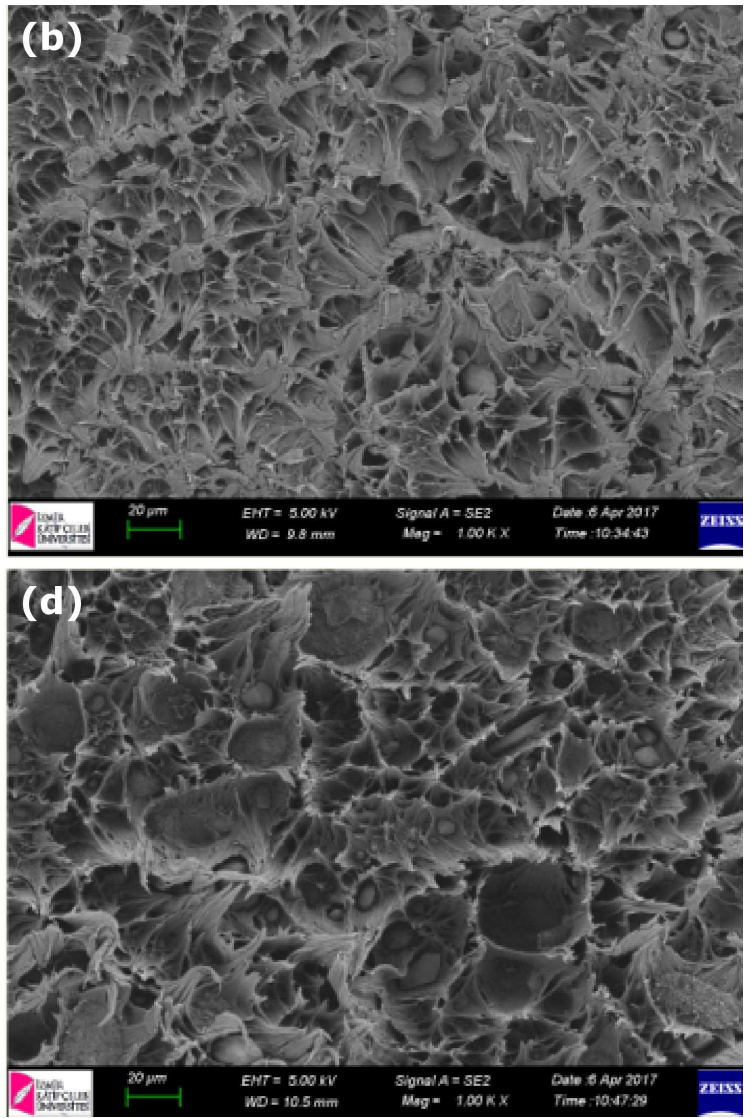

Fig. 4. SEM images of composites: (a) HDPE-5DA, (b) HDPE-10DA, (c) HDPE-15DA, and (d) HDPE-20DA. 


\section{Conclusion}

This study demonstrated that DA can be used as an efficient filler material for HDPE matrix. DA filling into the HDPE matrix has not led to considerable variation in the tensile and flexural strength of HDPE. However, the tensile and flexural moduli of HDPE increased with the addition of DA in the studied weight fraction range of $5-20 \%$. At lower temperatures, storage modulus values of HDPE-5DA are lower than those of HDPE, which may be attributed to pseudo lubricating effect of DA particles when used at low weight fraction. However, the storage modulus values of HDPE-10DA, HDPE-15DA, and HDPE-20DA are larger than those of HDPE because of the mechanical restraints exhibited by DA particles. DA filling into HDPE at increasing weight fractions from $5 \mathrm{wt} \%$ to $20 \mathrm{wt} \%$, increased the $\alpha$ transition temperature of HDPE, at which maximum dissipation of heat occurs.

\section{References}

[1] J.Z. Liang, J. Appl. Polym. Sci. 78, 759 (2000).

[2] D. Bahford, Thermoplastics: Directory and Databook, Chapman \& Hall, London 1997.
[3] R. Yang, Y. Liu, J. Yu, K.H. Wang, Polym. Degradat. Stabil. 91, 1651 (2006).

[4] C. DeArmitt, R. Rothon, Plast. Additiv. Compound. 4, 12 (2002).

[5] J.Z. Liang, Q.Q. Yang, J. Thermoplast. Compos. Mater. 20, 225 (2007).

[6] S. Karrad, J.M.L. Cuesta, A. Crespy, J. Mater. Sci. 33, 453 (1998).

[7] P.L. Cong, S.F. Chen, H.X. Chen, Construct. Build. Mater. 30, 495 (2012).

[8] X.N. Li, J. Luo, J.Z. Li, Q. Gao, J. Appl. Polym. Sci. 133, 44095 (2016).

[9] P.A. Ciullo, Industrial Minerals and Their Uses: A Handbook and Formulary, Noyes Publ., New Jersey 1996.

[10] J. De Sousa, Ph.D. Thesis, Loughborough University, UK 1984.

[11] S. Simsek, I. Ozen, J. Eng. Sci. Des. 4, 157 (2016).

[12] K. Sewda, S.N. Maiti, Polym. Bull. 70, 2657 (2013). 